\title{
Dental Bleaching Techniques; Hydrogen-carbamide Peroxides and Light Sources for Activation, an Update. Mini Review Article
}

\author{
Leandro Féliz-Matos ${ }^{*}$ Luis Miguel Hernández and Ninoska Abreu
}

Department of Academic Research/School of Dentistry, Universidad Iberoamericana, UNIBE. Santo Domingo, Dominican Republic

\begin{abstract}
Hydrogen and carbamide peroxides have been successfully used for many years; in the past century the dental bleaching technique suffered several changes and almost 10 years before new millennium the technique was finally recognized by the international agencies of regulation.

It is important that Dentists handle the peroxides with the essential knowledge, because it is demonstrated that satisfactory final results of this technique depend on the correct diagnosis of stains, management of the substrates (enamel and dentin) and as well sensitivity.

Dentists are exposed to several dental bleaching techniques, products and brands, and in the last 2 decades the devices for light activation of the peroxides have become an extensive catalog. Today, the technique is also suffering changes based on the effectiveness of the different light sources for peroxide activation and its relation to satisfactory final results of the technique.

The purpose of this literature review is to explain the determinant factors that influence satisfactory final results of the techniques and provide a general overview, in order to achieve a treatment decision based on evidence.
\end{abstract}

Keywords: Carbamide, hydrogen, peroxides, stains, sensitivity, vital tooth.

\section{INTRODUCTION}

Despite the large number of techniques described in the literature concerning the external bleaching of vital teeth, all are based on the direct use of hydrogen peroxide $(\mathrm{H} 2 \mathrm{O} 2)$ or its precursor, carbamide peroxide [1].

Minoux and Serfaty recognize that tooth whitening is a very complex process that depends on several factors: 1) the $\mathrm{pH}$ of the bleaching agent, 2) the method of application and thickness of the bleaching agent to the enamel, 3) the fluctuation of irradiation, 4) length of photoactivation, 5) tooth size, 6) selective absorption of the wavelength of irradiation, among others. Further studies are needed regarding the new wavelength of the laser lights and whitening products to determine the protocol and the most favorable terms in order to improve the process of tooth whitening $[1,2]$.

To date, two techniques of tooth whitening have been described: 1) Ambulatory (at home) that needs an intraoral device (tray) to apply the gel of peroxide, this one is more cost-effective, the value of the dental color obtained is sustained for long periods; but important changes in this value

*Address correspondence to this author at the Department of Academic Research/School of Dentistry, Universidad Iberoamericana, UNIBE. Santo Domingo, Dominican Republic; Tel/fax: 809-689-4111;

Ext: 1500; E-mail: 1.feliz@prof.unibe.edu.do are not observed before $7^{\text {th }}$ day of the treatment; and 2) inoffice (by a professional) that uses photo-activation, this one allows changes in the color of the enamel from the first session, although there is strong evidence that the value of the dental color obtained is not sustained after 6 months [3-5].

Ameri confirmed on a study in Iran that the number of patients who wish to have tooth whitening treatment has increased by over $300 \%$ in the last 5 years; however, dentists often encounter the situation that patients prefer the office technique that involves photo-activation. There is evidence that photo-activation with Laser Light Emitting Diodes (LED) used on the in-office technique just turned out to be more advantageous than ambulatory technique, when compared with halogen lamps and lasers, noticing that in the ambulatory technique, the changes in the value of dental color are not observed up to 7 days of treatment. According to Sias and Abdul, the changes obtained in the value of the dental color through a home bleaching technique with $10 \%$ carbamide peroxide is held until 2 years after the procedure $[4,5]$.

Some authors claim that in general, patients desire pearl white teeth, since tooth color is one of the most important determinants for patient satisfaction [6]. White teeth have been linked to social competence, intellectual ability, successful interpersonal relationships, and even psychological stability [7]. 
Table 1. Concentrations, use and brands of hydrogen and carbamide peroxides.

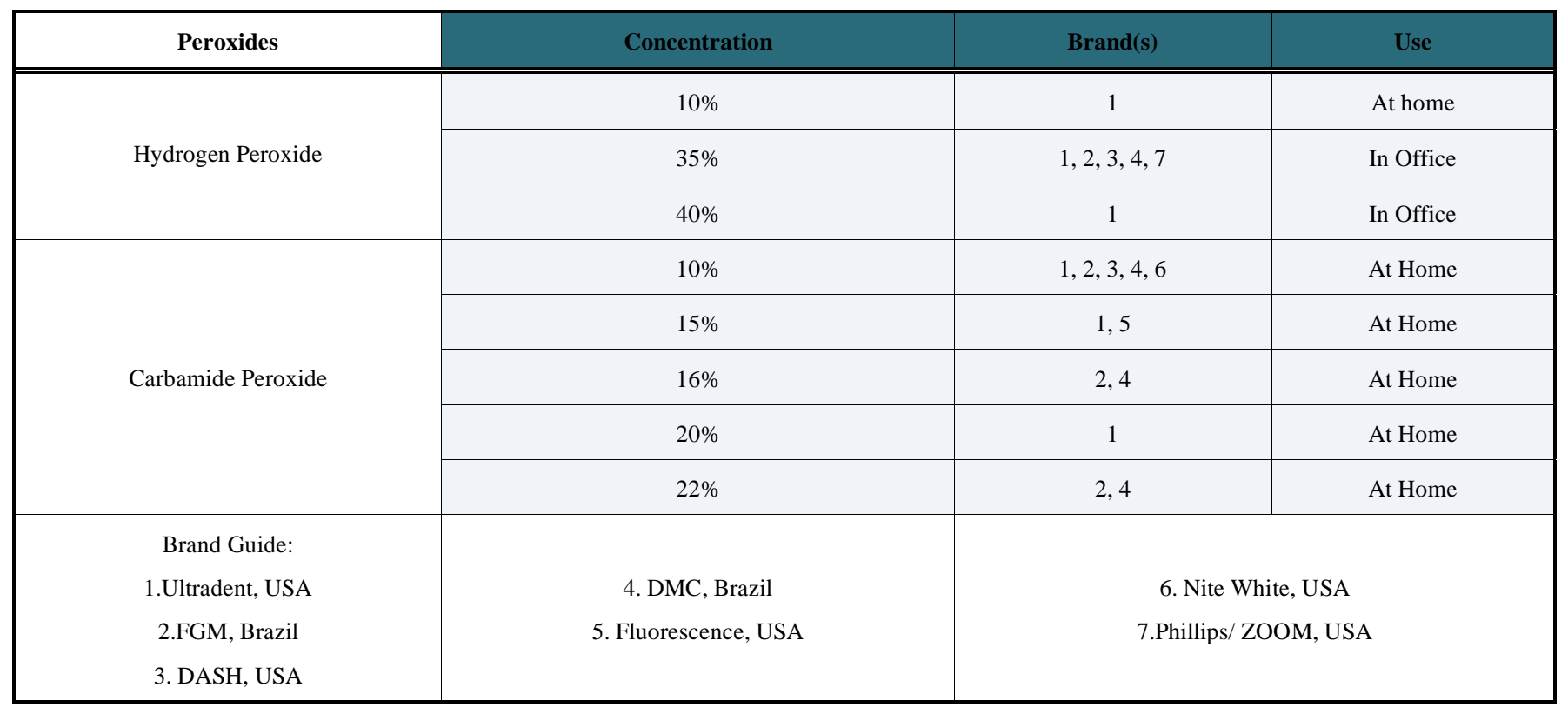

\section{BACKGROUND}

Whitening enamel that is composed of one or more abnormal stains, returns to its original color and translucency to the possible maximum extent. To achieve this goal, there are several techniques and numerous bleaching chemicals, such as hydrogen peroxide and carbamide peroxide in different concentrations, which are ambulatory or used in-office [8, 9].

In the west, tooth whitening is an old treatment and not unique to today's society. For over 100 years, the hydrogen peroxide (oxygenated water) has been used, as well as hydrochloric acid, together or separately, for internal bleaching (non vital teeth) or external bleaching (vital teeth) $[8,9]$.

Haywood and Heymann recommended the use of a gel of $10 \%$ carbamide peroxide (equivalent to $3.6 \%$ hydrogen peroxide) applied with a thin plastic individualized tray for each patient and its use for several hours a day at home for a period of 1-2 weeks. This was the origin of today's most widespread and economic bleaching technique (ambulatory), having the advantage of relying on bleaching substances at very low concentration, therefore, many products of this category are available in the market $[8,9]$.

Today, most dentists use hydrogen and carbamide peroxide gels between $10-40 \%$, which are chemically activated or by different light sources, such as halogen light, laser or plasma arc [9], See (Table 1).

\section{SUBSTRATES: ENAMEL AND DENTIN}

Tooth enamel, according to Schwartz and Robbins, is a hard-calcified tissue that completely surrounds the crown of a human tooth. It is vitreous, and possesses a shiny surface. The color of the enamel varies from pearl white to dark yellow, as the color of the dentin that supports it. In the composition of the enamel, the mineral salts have a proportion of $90 \%$, the remaining $10 \%$ consist water and organic sub- stances. The inorganic substances are enamel crystals that consist predominantly of apatite. The enamel is also composed of small amounts of calcium carbonate, sodium, potassium and magnesium, carbon dioxide, varying amounts of phosphorus and fluorine. Enamel is the substrate par excellence for vital teeth bleaching, where peroxides are applied [10]. Peroxides can induce remineralization and repair the enamel over time after the transient demineralization that occurs during the whitening process [11].

Dentin, instead, is a hard-calcified tooth tissue that has the same exterior shape, in the coronal portion is coated with enamel and cementum. The dentin surrounds a central cavity called pulp chamber, which houses the dental pulp. It is yellowish-white, less hard than enamel but harder than bone. Its composition is given by $50 \%$ of mineral salts, $30 \%$ organic matrix and $20 \%$ water [10].

Schuartz et al., explain that the three main components of dentin are the fundamental substances, the tubules and fibers. The fundamental substance is a calcified matrix and the tubules canaliculi are vertebrates that house the fibrils, which are extensions of the odontoblast. Dentin is a substrate that is not directly related to the peroxide used in bleaching of vital teeth, but plays an active role in the phenomenon of sensitivity [10].

\section{PIGMENTATIONS/STAINS}

According to Moncada, Arangüiz and Urzúa, extrinsic pigmentations are usually produced on the surface of the tooth. The attraction of different materials to the tooth surface plays a critical role in the deposition of extrinsic pigmentations. There is involvement of electrostatic and Van Der Waalas forces, acting for long periods of time, as well as hydrophobic effects, dipole forces and hydrogen bonds acting for short periods of time. These interactions allow the chromogenic agent to pre-reach the surface of the tooth determining the occurrence of the pigmentations [12]. 
Such pigmentations can be classified into the following:

N1: type of direct dental stain with chromogenic bind to the tooth surface. The color of the chromogen is similar to that of the dental stains; such as stains by tea, coffee, wine, metals and bacterial products [9].

N2: type of direct dental stain with colored materials that change tooth color after joining the surface. Pigmented materials are initially bonded to the surface of the tooth and then change the color. Typical example is yellow-pigmented plaque or coffee on inter-proximal or cervical areas [9].

N3: type of indirect dental stain with colorless materials or pre-chromogens that bind to teeth, carrying a chemical reaction that causes the dye to convert to chromogens and pre- chromogens, such as fluoride or chlorhexidine [9].

Most of the extrinsic pigmentations can be treated with mechanical or chemical coloring renewal techniques, and advising the patients about their habits and prevention mechanisms to avoid surface stains [9].

The intrinsic pigmentations are those that involve the thickness of the tooth, located in the enamel or dentin. They consist of deep pigmentation, and are difficult for therapeutic options or therefore constituting a clinical challenge to find a solution. This is the case of pigmentation by tetracycline, different degrees of "enamel hypoplasia", "fluorosis", "dentinogenesis imperfecta", among others [12].

Santana describes the presence of a natural tooth color space, named as a "sub-shaped banana", this space is located between the light red and light yellow, elongated and extended parallel to the axis of light; the extreme values (the lighter and the darker tooth) corresponding to the value of dental color, which is measured in different systems, manual or digital [13].

\section{MECHANISM OF ACTION OF THE PEROXIDES}

According to Minoux et al., the methods that have been described in the literature for bleaching vital teeth are all based on the direct use of hydrogen peroxide $\left(\mathrm{H}_{2} \mathrm{O}_{2}\right)$ or its precursor, carbamide peroxide [1].

Hydrogen peroxide is an oxidizing agent that is able to produce free radicals $\left(\mathrm{H}_{2} \mathrm{O}+\mathrm{O}_{2}\right)$, which are very reactive; in a purely aqueous state, the hydrogen peroxide is slightly acidic. The result is the perhydroxyl $\left(\mathrm{HO}_{2}\right)$ that is the most potent free radical. To be able to promote the formation of the ion perhydroxyl, hydrogen peroxide needs to become alkaline; the optimum $\mathrm{pH}$ for this to occur is of 9.5 to 10 [7, 9].

In the ionization of hydrogen peroxide buffered by this $\mathrm{pH}$, a large amount of $\mathrm{H}_{2} \mathrm{O}$ perhydroxyl free radicals are found, which result in a higher bleaching effect in the same amount of time. The most common concentration of hydrogen peroxide is $35 \%$ [7].

Moncada et al., have identified the carbamide peroxide typically in concentrations from $3 \%$ to $20 \%$. It is decomposed into hydrogen peroxide $(10 \%$ carbamide peroxide produces $3.6 \%$ hydrogen peroxide) [12]. These products contain carbamide peroxide with carbopol or glycerin base.
Carbopol base decreases the release time of hydrogen peroxide, but it does not change the effectiveness of treatment. The carbamide peroxide preparations have a slightly acidic pH. [12]

There is evidence that peroxides can diffuse through the pulp, this phenomenon occurs depending on the time of contact with the substrates and the concentration of it; abnormalities on the enamel surface influence this diffusion. Most of the studies confirm that with these conditions in control, the inflammation of the pulp caused by dental bleaching is reversible [1, 14].

The success of the dental bleaching technique is directly related to the ability of penetration or diffusion of the peroxides into enamel and dentin [1, 14].

The ambulatory technique for vital teeth bleaching uses carbamide peroxide between 10 and $22 \%$, three clinical sessions are required to reduce at least one scale of color's value on the Vita shade guide. Carbamide peroxide is placed on the teeth by the patient at home for a period of 8 hours usually overnight, and for a time no longer than 3 weeks, until a favorable change of color is observed. It is important not to exceed the time recommended by each manufacturer in order to avoid the point of saturation where peroxides can become harmful for the teeth $[8,12]$.

The in-office technique of vital teeth whitening, uses 35$40 \%$ hydrogen peroxide and usually a light source; four sessions are allowed, the time of exposure of the patient to the application of the peroxide is 15 to 20 minutes per session to obtain a favorable change of color; it is not recommended to exceed this time [12]. A recent in-vitro study indicates that with less time of exposure, there is less toxicity to the pulp and the final results of color are very satisfying [15].

\section{SENSITIVITY}

One of the most controversial side effects of dental bleaching is the phenomenon of sensitivity [16]. Various theories are described in connection with tooth sensitivity that occurs during bleaching and are as follows:

Direct innervation theory: direct nervous endings that penetrate the dentin and then the enamel-dentin junction, when mechanical stimulation is received, sensitivity occurs [16].

Theory of the odontoblast as a receptor: the odontoblast acts as receptor itself sending the signal to a nerve ending, but many studies have determined that these cells are not excited [16].

Hydrodynamic theory: is defined as any stimulus that produces tooth fluid movement (dental lymph) and the movement of fluid within the tubules recipients stimulates innervation on the dentin-enamel junction $[9,12]$.

Meglani et al., defined the hydrodynamic theory, as dentinal tubules that are open widely and generate fluid movement within them, this fluid is spin-dried and acts on nerve endings or the dentino-pulpar complex; the hydrodynamic theory is the most widely accepted and is believed that is present during the application of the peroxides [16]. 
Some substances used for the treatment of tooth sensitivity are: potassium nitrate, sodium fluoride, calcium phosphate, fluoride varnishes and adhesives [16].

Several authors specified that sensitivity when is present, during or after bleaching is a totally controlled adverse side effect that can be managed easily with peroxides that includes fluor on its composition, or applying potassium nitrate; this situation can also be prevented [3, 17].

One important factor to address is that the patient has to be aware that sensitivity can occur, it is a responsibility of the dental staff to communicate this to the patient and provide solutions to treat the symptoms [18-20].

\section{LIGTH SOURCES}

The most popular tooth whitening is performed in the dental office, and mostly used with $35 \%$ hydrogen peroxide, using heat or a light source to enhance the action of the peroxide; as Ferrarazi et al., pointed out, the light sources or laser based photo-activation most commonly used in dentistry are: $\mathrm{CO}_{2}$ argon laser and diode laser; argon laser requires extreme care by the length of emitting wavelength and the thermal properties [3].

In the case of the laser LED, this is more favorable because it emits a blue light with high energy photons that efficiently stimulate the hydrogen peroxide molecule, without the thermal side effect, the great disadvantage of this is the high cost [3].

There are other types of lasers that are called, "the low level laser or diode laser", their mechanism of action functions as a solid arsenate semiconductor generally associated to aluminum, gallium and indium and the electrical energy is converted into laser energy. The wavelength of diodes is well absorbed by the pigmented tissue because they are absorbed by the hard tissues and do not generate heat, also the size of the lamp is manageable and it is available at low cost [3].

Some peroxides diffuse more quickly when activated chemically [21]. Ferrarazi et al., concluded that LED lamps are effective, safe and inexpensive to activate the hydrogen peroxide, [3] while Klaric on a temperature rise study stated that Zoom2 lamp compared to LED-405 lamp produced larger increments of temperature to the pulp [21, 22].

Dominguez et al., stated that the LED lamps are effective and do not produce more than 5.5 degrees (celcius) of temperature increase to the pulp [2].

These days manufacturers of peroxides are encountering the challenge of redefining and redesigning the indications and concentrations based on several studies that show strong evidence that light sources do not represent an improvement anymore for the in-office dental bleaching technique [21, 22].

\section{DISCUSSION}

Amaral, et al., found that vital teeth bleaching based on hydrogen and carbamide peroxide do not produce morphological changes to the enamel. However, in another study a minimal reduction in enamel hardness and some histomorphological changes were found when using 35\% hydrogen peroxide in a cariogenic environment [23, 24].

In vital teeth whitening, dental pulp is stimulated to a possible thermal change (sensitivity), this is believed to be reversible, therefore not representing danger or causing permanent damage to this important organ [1].

Sensitivity during whitening of vital teeth is associated to high concentrations of peroxide and exposure time to dental structures, and this sensitivity during bleaching is typically moderate and can be easily controlled [25-27].

Regarding the knowledge of the effects of the use of light sources, there is no evidence that these when used to activate the hydrogen peroxide improve its mechanism of action and thus the effect of tooth whitening, furthermore no association is known or a benefit relationship with the type of stain, the concentration of peroxide and enamel thickness $[2,26]$.

It is also important to address what several authors confirm, that there is a direct relation of the following principle: at less time of exposure of the tooth to the peroxide, there is less toxicity to the pulp, and at more time and less concentration, more satisfactory color results are obtained [25-29].

Hahn, et al., concluded that photo- activation of peroxides for dental bleaching alone is not beneficial, color is not stable over three months, and the increase in temperature caused to the pulp is important, this is consistent with Torres et al., who described that bleaching vital tooth through photo-activation based on diode lasers of low intensity is fast and intense but regression of color was observed before 12 months. Other studies have shown no statistically significant difference on changes of value of the dental color when using light activation [26, 30, 31].

According to Mon, et al., multiple studies conclude that patient's satisfaction is not related to the type of treatment received if the results are satisfactory [6].

Current trends on international research in the literature are directed to the study of the mechanisms to evaluate the measure, production of color and the advances in photo- activation based on currently known techniques [13, 2].

Certain bleaching manufacturers have recommended recently to avoid the use of light sources and have increased the concentrations of the Hydrogen Peroxides to $40 \%$, based on studies previously shown [32].

\section{CONCLUSION}

Hydrogen and carbamide peroxides are secure options for bleaching vital teeth, maintaining the substrates healthy. It is very important that dentists possess the necessary knowledge of these substrates and also the management of the peroxides.

Light activation is not advantageous, nor for the final results of the bleaching techniques, neither to accelerate the mechanism of action of the peroxides

It is demonstrated that sensitivity is a temporary side effect, and when it is present, normally is not worst than moderate. 
There are different substances to treat sensitivity during the treatment, with evidence that most of them are effective.

Time is a very important factor on dental bleaching, as the diffusion of the peroxides through the substrates.

\section{CONFLICT OF INTEREST}

The authors confirm that this article content has no conflicts of interest.

\section{ACKNOWLEDGEMENTS}

None declared.

\section{REFERENCES}

[1] Maryline M., Rene S. Vital tooth bleaching-biologic adverse effects- a review. Quinten Publ 2008; 39: 645-59.

[2] Dominguez A, Garcia J, Costela A, Conez C. Influence of the light source and bleaching gel on the tooth whitening process. Health Wellness Reso Cent 2011; 29: 53-7.

[3] Ferrarazi M, Huck C, Machado M. A vital tooth bleaching technique with a compound light system led. J Oral Laser Applic 2003; 3: $167-72$

[4] Ameri H. Effects of different bleaching time interval on fracture toughness of enamel. J Conser Dent 2011; 14: 73-5.

[5] Grobler SR, Majeed A, Moola MH, Rossow RJ, van Wyk Kotze T. In vivo Spectrophotometric assessment of the tooth Whitening Effectiveness of Nite White $10 \%$ with Amorphous Calcium Phosphate, Potassium Nitrate and Fluoride, Over a 6-month Period. Open Dent J 2011; 5: 18-23.

[6] Mon T, Norkhafizah S, Nurhidayati H. Factor influencing patient satisfaction with dental appearance and treatments they desire to improve aesthetics. BMC Oral Health 2011; 11: 6. doi:10.1186/1472-6831-11-6.

[7] Sun L, Liang S, Sa Y, et al. Surface alteration of human tooth enamel subjected to acidic and neutral $30 \%$ hydrogen peroxide. J Dent 2011; 39: 686-92.

[8] Golsdtein G. Complete Dental Bleaching. $1^{\text {st }}$ ed. USA: Quint Public 1995.

[9] Lugo V, Campillo P, Feliz L. Efectos de los agentes blanqueantes usados en el blanqueamiento dental vital ambulatorio supervisado sobre los tejidos blandos y los tejidos dentales. Doctor en Odontología. Escuela de Odontología ,Universidad Iberoamericana: UNIBE Santo Domingo, DR 2003.

[10] Schwartz R. Fundamentos en Odontología operatoria. $1^{\text {st }}$ ed. Colombia: D'vinni editorial Ltda 1999.

[11] Chen X, Chen Z, Lin Y, Shao J, Yin L. Effects of tooth whitening agents and acidic drink on the surface properties of dental enamel. Clin Oral Investig 2013; Available from: http://www.ncbi.nlm.nih.gov/pubmed/24298810

[12] Moncada C, Gustavo A, Vicente U. Blanqueamiento en Odontología. 1ed. Chile: n/a 1999.

[13] Santana J. Blanqueamiento dental: estudio clínico para el desarrollo de métodos estadísticos e inteligentes para la predicción del cambio cromático, tesis doctoral. Doctora en Odontología. Facultad de odontología, Universidad de Granada, España 2010.

[14] Bharti R, Wadhwani K. Spectrophotometric evaluation of peroxide penetration into the pulp chamber from whitening strips and gel: An in vitro study. J Conserv Dent 2013; 16: 131-4.

[15] Soares DG, Basso FG, Hebling J, de Souza Costa CA. Concentrations and application protocols for hydrogen peroxide bleaching gels: Effects on pulp cell viability and whitening efficacy. J Dent 2014; 42: 185-98.

[16] Miglany S, Aggarwal V, Ahuja B. Dentin hipersesivity: Recent trends in management. J Conserv Dent 2010; 13: 218-24.

[17] Mondelli RF, Azevedo JF, Francisconi AC, Almeida CM, Ishikiriama SK. 17 Comparative effectiveness of different dental bleaching methods - two year follow-up. J Appl Oral Sci 2012; 20(4), 435-43.

[18] Mehta D, Venkata S, Naganath M, Linga RU, Ishihata H, Finger WJ. Clinical trial of tooth desensitization prior to in-office bleaching. Eur J Oral Sci 2013; 121: 477-81.

[19] Bruzell EM, Pallesen U, Thoresen NR, Wallman C, Dahl JE. Side effect of external tooth bleaching: a multi-centre practice-based prospective study. Br Dent J 2013; 215(9): E17. Doi: 10.1038/sj.bdj.2013.1047.

[20] Do Carmo Publio J, D'Arce MB, Ambrosano GM, et al. Efficacy of tooth bleaching with the prior application of a desensitizing agent. J Investig Clin Dent 2013; Doi:10.1111/jicd.12074.

[21] Torres CR, Souza Cs, Borges AB, Huhtala MF, Caneppele TM. Influence of concentration and activation on hydrogen peroxide diffusion through dental tissues in vitro. Sci World J 2013; Doi:10.1155/2013/193241

[22] Klaric E, Rakic M, Sever I, Tarle Z. Temperature rise during experimental light-activated bleaching. Lasers Med Sci. 2013 Jun 19. Available from: http://www.ncbi.nlm.nih.gov/pubmed/23780710

[23] Do Amaral FL, Sasaki RT, da Silva TC, França FM, Flório FM, Basting RT. The effects of home-use and in-office bleaching treatments on calcium and phosphorus concentrations in tooth enamel: an in vivo study. J Am Dent Assoc 2012; 143: 580-6.

[24] Arruda A, Santos P, Sundfeld R, Berger S, Briso A. Effect of Hydrogen Peroxide at $35 \%$ on the morphology of enamel and Interference in the de-remineralization Process: An In Situ Study. Oper Dent 2012; Available from: http://www.ncbi.nl-m.nih.gov/pub$\mathrm{med} / 2-2433029$

[25] Al-Harbi A, Ardu S, Bortolotto T, Krejci I. Effect of extended application time on the efficacy of an in-office hydrogen peroxide bleaching agent: an in vitro study. Eur J Esthet Dent 2013; 8: 22636.

[26] Nutter BJ, Sharif MO, Smith AB, Brunton PA. A clinical study comparing the efficacy of light activated in-surgery whitening versus in-surgery whitening without light activation. J Dent 2013; 41 (Suppl 5):e3-7. Doi: 10.1016/j.dent.2013.03.004.

[27] Basting R, Amaral F, France F, Florio F. Clinical comparative study of the effectiveness of and tooth sensitivity to $10 \%$ and $20 \%$ carbamide peroxide home-use and 35\% and 38\% hydrogen peroxide in-office bleaching material containing desensitizing agents. Oper Dent 2012; Available from: http://www.ncbi.nlm.nih.gov/pub-med/22616927

[28] Machado LS, de Oliveira FG, Rocha EP, et al. Clinical trial evaluating color change and tooth sensitivity throughout and following in-office bleaching. Int J Periodont Restorat Dent 2013: 33: 209-15.

[29] Bruzell EM, Johnsen B, et al. In vitro efficacy and risk for adverse effects of light-assisted tooth bleaching. Photochem Photobiol Sci 2009; 8(3): 377-85.

[30] Hahn P, Schondelmaier N, Wolkewitz M, Altenburgeu MJ, Polydorou O. Efficacy of tooth bleaching with and without light activation and its effect on the pulp temperature: an in vitro study. Odontology 2012; Available from: http://www.ncbi.nlm.nih.gov/pub$\mathrm{med} / 22395767$

[31] Torrez CR, Barcellos DC, Batista GR, Borges AB, Cassiano KV, Pucci CR. Assesment of the effectiveness of light-emitting diode and diode laser hybrid light sources to intensity dental bleaching treatment. Acta Odontol Acand 2011; 69:176-81.

[32] URL:https://www.ultradent.com/en-us/Dental-ProductsSupplies/Tooth-Whitening/In-Office-Whitening/OpalescenceBoost-PF-40-percent/Pages/default.aspx. May 25,2014 (http://creativecommons.org/licenses/by-nc/3.0/) which permits unrestricted, non-commercial use, distribution and reproduction in any medium, provided the work is properly cited. 